\title{
On the Establishment of Green Fiscal Transfer Payment Mechanism in Northwest Ethnic Regions of China
}

\author{
Afan $\operatorname{Sun}^{1}$ \\ ${ }^{1}$ School of Economics, Northwest University for Nationlities, Lanzhou, China \\ Correspondence: Afan Sun, School of Economics, Northwest University for Nationlities, No.589 Gannan Street, \\ Lanzhou, Gansu, China. Tel: 86-931-881-4376. E-mail: sunaf02@126.com
}

Received: January 9, 2014

Accepted: January 24, 2014

Online Published: March 31, 2014

doi:10.5430/ijfr.v5n2p102

URL: http://dx.doi.org/10.5430/ijfr.v5n2p102

The article supported by the Fundamental Research Funds for the Central Universities (zyz2011015).

\begin{abstract}
The building of a resource-saving and environment-friendly society has become one of the important tasks in China, which makes for promoting economic, culture, social, and ecological civilization development in accordance with the overall arrangements for the cause of Socialism with Chinese characteristics. The layout of the strategy of development priority zones is conductive to realize the goal. According to the strategy of development priority zone's special ecological protection requirements of the Northwest Ethnic Regions, the paper holds that it should be build up the special green fiscal transfer payment mechanism in the region. It designs specific framework to ensure the implementation of the strategy of development priority zones.
\end{abstract}

Keywords: development priority zones, northwest ethnic regions of China, green fiscal transfer payment, ecological environment protection

\section{Introduction}

With the development of the society economic, the environmental pollution is becoming more and more serious. According to the experts, the loss of GDP caused by pollution has reached $10 \%$ in China. In order to solve these problems, the central government arranges the strategy of development priority zone. Report to the Eighteenth National Congress of the Communist Party of China made a definite request that "We should ensure the speedy implementation of the functional zoning strategy and require all regions to pursue development in strict accordance with this strategy, and advance urbanization, agricultural development and ecological security in a scientific and balanced way." The government of China also emphasizes the fact that the strategy of development priority zones is the primary task to improve development of China's geographical space, and to promote the construction of ecological civilization. For the special ecological and geographical environment, the Northwest Ethnic Regions plays an important role in building the ecological civilization. How to adapt to the national macro layout under the current conditions, and implement the special strategy of development priority zones, has become an urgent problem in the western minority areas.

There is a vast and rich literature on the transfer payment of china. The relationship between the local economic development and the transfer payment has been widely analyzed in last decade. Many studies have shown that the financial transfer payment plays an important role in developing economy of ethnic minority regions.

Jijiang Liang \& Yong Huang (2003) studied the relationship between the financial transferable payment and the social public affairs, and thought it is of importance for development of social public undertakings, enforcement of social guarantees, development of basic facility constructions, and stability of border securities. While, the current system has some problems, only constructing the special system of financial transferable payment in ethnic regions can the equality and efficiency of financial transferable payment be ensured.

Jianxia Ma (2007) and Yuling Wang (2008) posed that as an important way to supply the development of the underdevelopment areas, the financial transfer payment has its own features for the ethnic areas, but there existed some obvious problems and we must optimize the overall supply, structure, and distribution system of the financial transfer payment. 
At the same time, beginning from the tax return and systematic compensation, fiscal transfer and special transfer payments, Zhenyang Lei \& Aihua Cheng (2009) studied the balanced effect of the transferring payment on the ethnic areas, and pointed that the ethnic areas transfer payments have the best balanced effect, especially the general transfer payments have more obvious effect, and the special transfer payment is good for the balance effect, and needs to be improved.

Xudong Wu \& Jiancong Wang (2011) found because of the bad geographical natural environments and the high supply costs of public service, local finances of ethnic areas are unable to provide the public service as the average gross. Jie Mao, Dehu Wanga \& Chongen Bai (2011) also used both the county-level and province-level data in China over the period 1993-2003 to test the theoretical findings by using the method of DID with propensity score matching, and found the fiscal transfers for ethnic regions significantly improve both level and composition of ethnic regions' spending, while not significantly reduce the gap of economic development between ethnic regions and others. The future of China's financial transfer payments shall take the equal public services goals as the reform direction.

While there has seldom studies about the relationship between the financial transfer payment and ecological protection, except for Dongmei Zhang (2012) demonstrates that the financial transfer payment is the most immediate method and most powerful tool for ecological compensation in the minority areas of China. The central and local governments have made some achievements in this aspect but some problems still remain, and we should introduce some incentive compatible mechanism to solve them.

In recent years, the conflicts between the fast economic social development and pressure of resources are increasing outstanding, especially in under-developed West of China. The paper proposes that the government should take effective measures to help the Northwest Ethnic regions to protect environment under the strategy of development priority zones.

\section{The National Strategy of Development Priority Zones and Its Requirements}

The national strategy of development priority zones means the state should determine the main body function in different areas through making an overall plan and arrangement about the distribution of population and economy, and the pattern of land usage and urbanization, gradually form its spatial order of national land use, which coordinated with population, economy and resource environment, according to the resource and environment carrying capacity, and the existing development intensity and potential in different region.

The Major Function Oriented Zone is a new concept initiated by the "Eleventh-Five-year-plan". It's an important theoretical innovation. According to the development mode, the China's geographical space is rational defined into optimized development areas, key development areas, restricted development areas and prohibited development areas. In 2011, the construction of main function area is formally defined as one of the national strategies in the Twelfth Five Year Plan.

Currently, according to the national economic layout, the four main functional areas are located in different economic roles and are responsible for different social function. Some urbanized areas with more developed economy and densely population, and worse resource environment are called the optimized development zones, whose main duty is to change the mode of economic growth and enhance the level of competition in the global division of labor. The key areas for development have great development potential and their environment carrying capacity is strong. Their duties are gradually becoming more important carrier and congeries of population and economic development. The restricted development zones are extremely suitable for the agricultural development for owning more farmland, or their environment carrying capacity is weak, concerning the regional and national ecological safety. Their duties are to enhance the comprehensive productivity of agriculture or to repair environment and to withstand natural calamities, guiding the migration in the direction of promoting development and becoming the key ecological function areas. The prohibited development regions are the nature reserves in accordance with the law. It needs to impose mandatory ecological protection. The development of illegal activities should be strictly forbidden. Adapting to the development function, the division and location makes a distinction between the area which is suitable for the economic development and the area which is suitable for the region ecological environment protection, guilds the advantage model of local development between economic growth and ecological protection, and leads population distribution and economic layout accordingly with resources and environment carrying capacity to spatial balance and optimal configuration among population, economy, resource and environment.

\section{Status quo: The Strategy of Development Priority Zones' Challenge to the Current Environmental Situation of Financial Expenditure in Northwest Ethnic Regions}

The northwest ethnic regions, including the whole territory of Xinjiang Uygur Autonomous Region and the Ningxia Hui Autonomous Region, and autonomous prefectures and autonomous counties in the Gansu and Ningxia Province, 
are located in the inland of China. There have obvious dual contradiction including rich resources coexist with fragile ecology, and the great growth potential coexists with relatively undeveloped in the modernization process. In the functional zoning strategy, only three key development areas are located in the Northwest ethnic regions, urban areas account for only $14.3 \%$ of the number of planning area. In 25 national key ecological function zones, there are 7 regions in the Northwest Ethnic Regions, accounting for $28 \%$ of the total planning area. All involved in 436 county-level administrative regions, located in Northwest Ethnic Regions are 73, accounting for $16.7 \%$. All these embody that ecological protection is the Northwest Ethnic Regions' main function. In the near future, the Northwest Ethnic Regions should combine the economic development and living standards organically to adjust the layout of economy and industrial structure, and to promote harmonic development between man and nature.

Since China's reform and opening up, the focus of China is to accelerate economic growth and enhance national strength quickly. Under the mode of fiscal decentralization and administrative centralization, the central government has strong control ability to local governments through deciding the promotion and appointment or removal of local officials. The fiscal decentralization matches with the administrative incentive, which makes the local government easily arrange the economic resources from self-interest, and reflect the different interest of different supply of public goods, under submitting to central authority and conforming to the anticipated target of macro-regulation. The vertical control mode is conductive to the upper government push forward reforms through administrative incentive to subordinate officials. On the other hand, the mode makes the assessment standard for political achievement tend to economic development. Local governments have partiality for the economical public goods, which can improve the performance and promotion, more than the non-economical public goods which have no direct contribution to economic growth and play a weaker externality. The economical public goods include transportation, energy, and communication. The non-economical public goods include environmental facilities, sanitation and health service, culture and education, social welfare services, and so on.

As one of the public consumer goods, the environmental protection' basic characteristics are non-rivalry and non-excludability, and utility overflow is obvious. Private investors are reluctant to involve in such product due to large-size of the threshold investment and its low return rate, and the environmental protection are mainly provided by the government. The environmental protection's property of non-economical public goods make the local government pay little attention to it in a long term, and invest little. According to the National Bureau of Statistics, from 2001 to 2011, the investment for environmental pollution treatment in the whole country comes to 3661.5 billion yuan, including urban environmental infrastructure, industrial pollution control, and the investment of "three simultaneous" concerning pro-environment devices of the construction program. And the average environmental investment accounts for 1.3 percent of the GDP. In international custom, only the whole society and the government's environmental protection investment accounts for 1.5 percent of the GDP or more, can they arrest its rapid environmental degradation. Only accounting for $3 \%$ or more, the environmental quality can be effectively improved. The investment of environmental protection in China is still inadequate. As the local government, for a long time, the Northwest Ethnic areas also attach importance to economic public goods and ignore the non-economic public goods, which can be reflected from the following illustration.

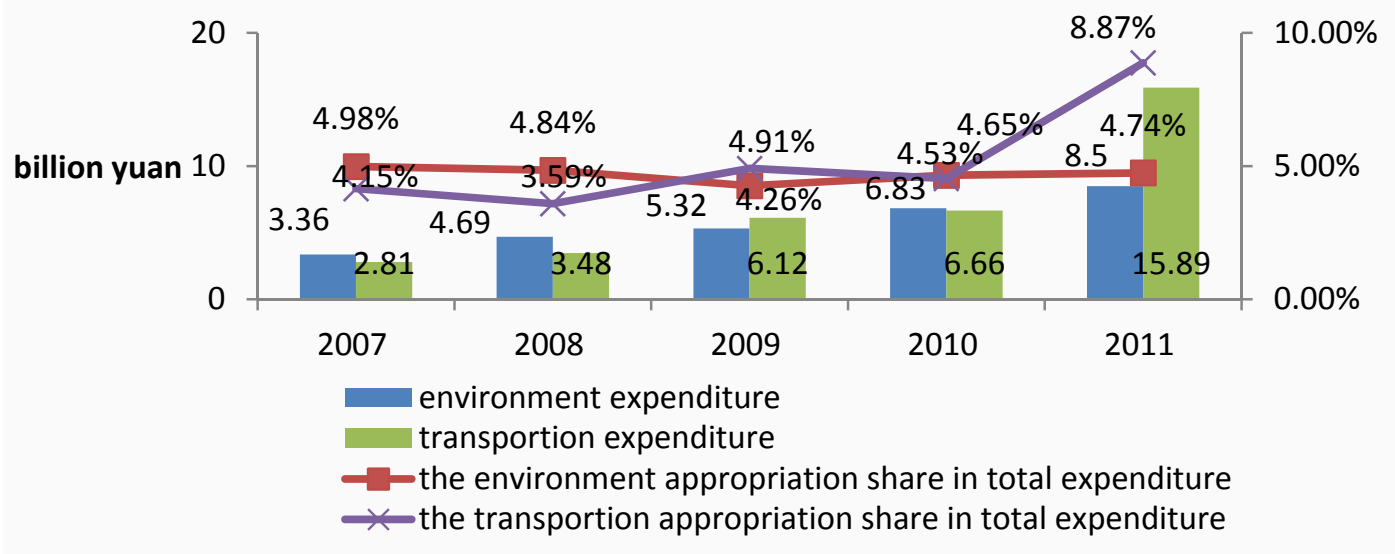

Figure 1. The environment and transportation expenditure and their appropriation share in total expenditure from 2007 to 2011 in Gansu (collecting and organizing data from the CEIC) 


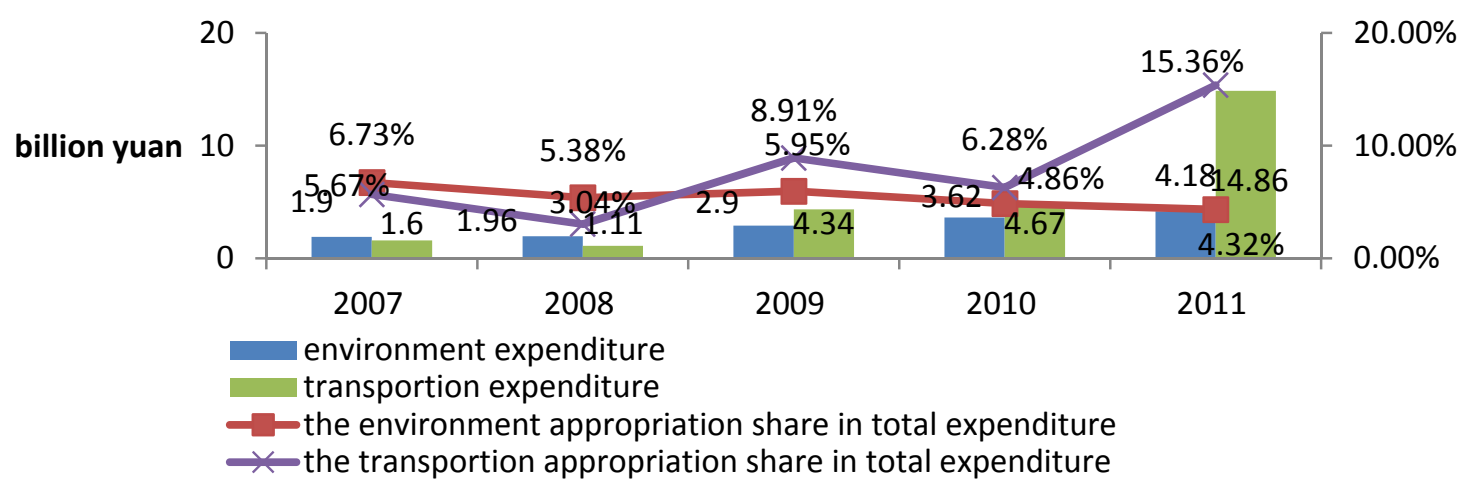

Figure 2. The environment and transportation expenditure and their appropriation share in total expenditure from 2007 to 2011 in Qinghai (collecting and organizing data from the CEIC)

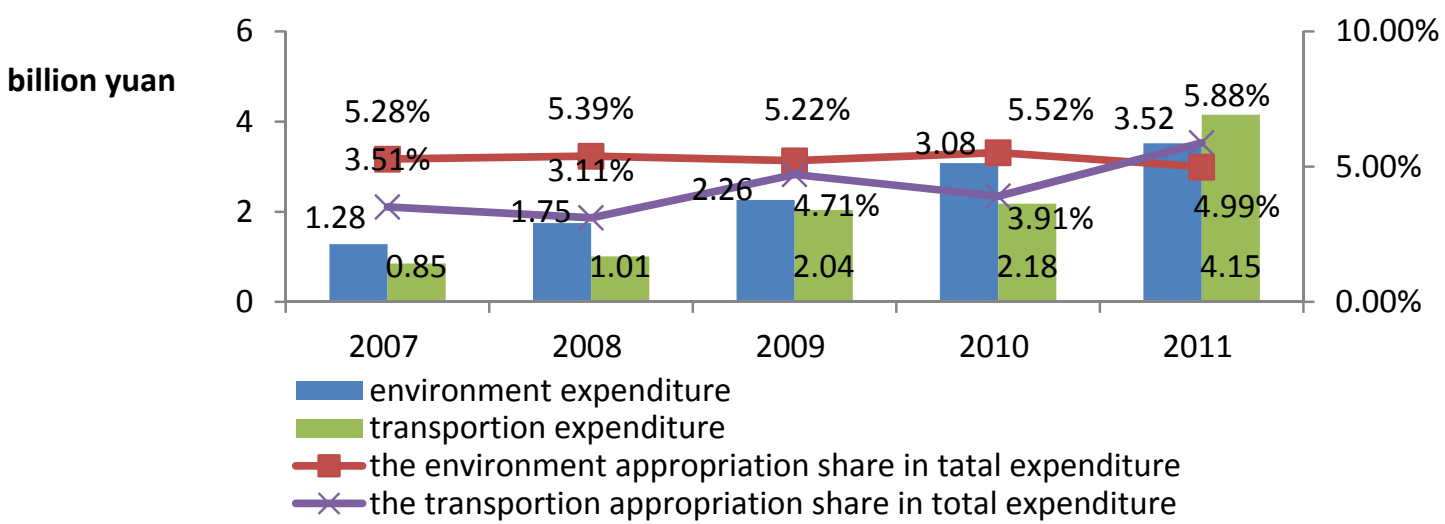

Figure 3. The environment and transportation expenditure and their appropriation share in total expenditure from 2007 to 2011 in Ningxia (collecting and organizing data from the CEIC)

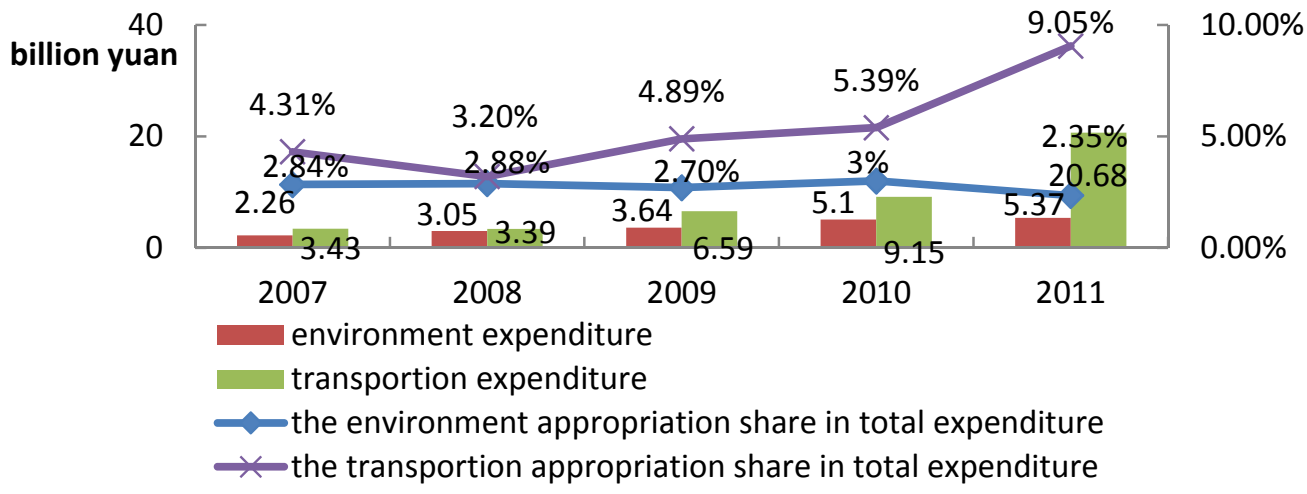

Figure 4. The environment and transportation expenditure and their appropriation share in total expenditure from 2007 to 2011 in Xinjiang (collecting and organizing data from the CEIC) 


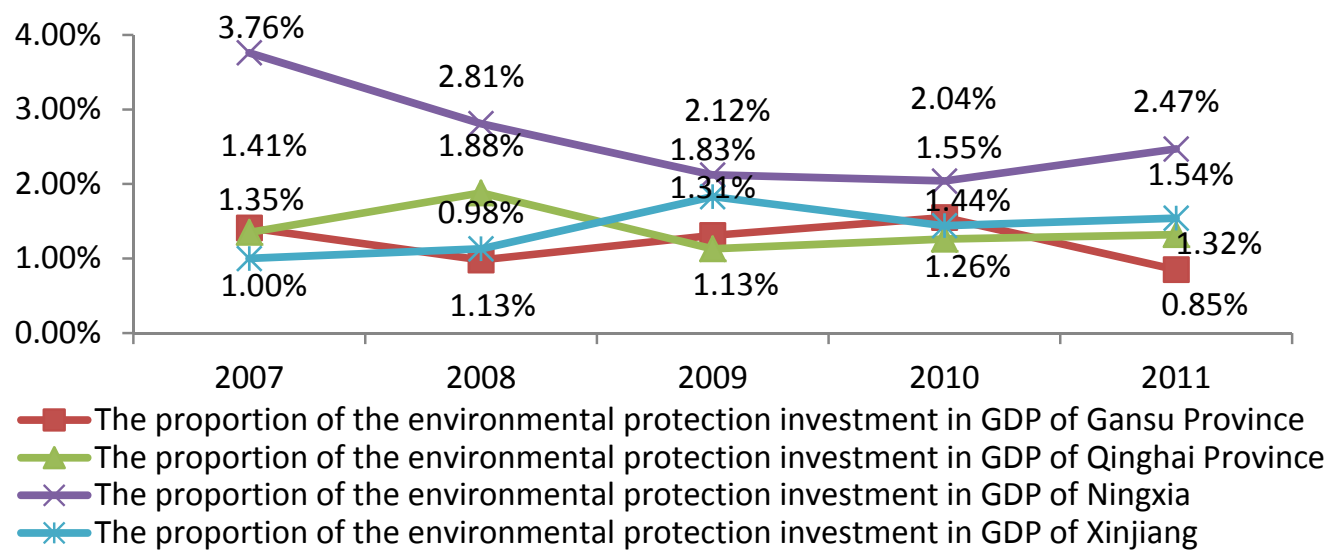

Figure 5. The proportion of environmental expenditure of Northwest Ethnic Regions account for respective GDP from 2007 to 2011

As can be seen from Figure 5, the proportion of environmental expenditure of Gansu, Qinghai, Ningxia and Xinjiang fluctuates in different years. While, except for Ningxia, the environmental investment of other three Provinces aren't continuing to account for 1.5percent of the GDP since 2007, let alone to reach the ideal standard of 3 percent. At the same time, from the Figure 1 to Figure 4, we know the expenditure on transport increased faster than the environment, especially from 2009.

\section{Countermeasures: Establish the Green Transfer Payment Mechanism Adapting to the Development Priority Zones}

Green financial transfer payment system is one part of the green finance. Green finance policy requires the health, safety, and civilization connotation of sustainable development into the public finance theory. In time, it considers both current and future. In space, it considers both economic development and environmental friendliness. And it should satisfy the various needs both at present and in the future. Then, the green transfer payment mechanism should conform to the planning of the main development priority zones, which not only meets the resource allocation mechanism of green economy to avoid relying on ecological debt for GDP growth, but also complies with the overall configuration of green finance to solve the absence of public finance on the ecological protection, and reflects the particularity of transfer payment to give full play to special function of the unrequited transfer of funds between government. The whole process can execute from the following:

\subsection{Perfect the Budget System}

Budget system is the core system of financial system in modern constitutional state, which not only tightly controls the financial activity itself, but also is one of the most effective tools of guidance, supervision and criticism of all administrative activities. The budget system's fundamental purpose is to ensure the government not deviating from the taxpayers' interests, and protect private property rights from the expansion of government power. In China, the budget system starts late. There still has some imperfect problems such as not-enough scientific and transparency, a mere formality in approving, liberty in budget enforcement and weakness in budget supervision and so on. And the transfer payment as a way of government expenditure with one-way free transfer, it has strict policy, flexible settings and variety, which makes the government budget often simply set out the framework without details, and only list the sum of the column regardless of the project, leaving innate blank for approving implementation and supervision. Therefore, to establish the green financial transfer payment mechanism, the budget system must be perfected. Only refining the environmental projects in the transfer payment and confirming the amount of fund from the source, can the evidence be investigated in the specific implementation..

On the one hand, it should stress the key point in the budget, and pool fund to strengthen weak links in economic and social development, reinforcing public services and social management. The general transfer payment shall give priority to make up for the monetary shortfall in restricted development areas and prohibited development regions, pushing forward the major functional oriented zone. While the special transfer payment shall divide and standardize 
the original ecological protection project in the northwest Ethnic Regions, and raise efficiency in fund utilization. On the other hand, the budget of local government should comply with the construction requirement for the development priority zones, and give priority to the available fund for ecological environment projection in the Northwest Ethnic Regions. To establish the mechanism for green financial transfer payment, it also should gradually from a mechanism for guaranteeing adequate basic financial resources for county governments, and strengthen the capital security responsibility of provincial government, guiding from top to bottom, implementing from the bottom to upper and supervising at all levels.

\subsection{Strengthen the Supervision of Using the Fixed Fund for the Fixed Purpose}

For a long time, scholars believe that the current transfer payment system is not perfect in China. Not only it fails to alleviate the problem of interregional disparity in financial capacity, but aggravates the regional imbalance in development. Therefore, it shall strengthen supervision and management of using the transfer payment funds for the specified purpose only to establish the green financial transfer payment mechanism, which adapting to the development priority zones.

\subsubsection{Continue to Strengthen the Chinese Government Information Openness System Construction}

To monitor the enforcement of environmental protection at any time, Chinese government should follow the practices of the OECD's budge transparency, and issue regular reports in white paper or other forms to disclose the information of the transfer payments' project and funds, especially special transfer payments.

\subsubsection{Improve the Supervision System of Government Responsibility}

Firstly, audit green fiscal transfer fund on a regular basis, avoiding the fund is used for any other purposes. Moreover, the NPC representatives should play the role of delegate to check on budget and fiscal transfers, and exercise their functions of self-discipline and supervision. Furthermore, the accountability mechanism in green financial transfer of funds should be established. Accountability mechanism plays an important role to make sure the policy is enforced, and fund is rationally used. On the premise of perfecting budget, the respective responsibility of local governments and related sectors to green fiscal transfer funds should be further clearly defined, and the constitutive of liability elements of committing the related obligations should be refined, punishment increased.

\subsubsection{Build a More Effective and Targeted Third-Party Supervision Mechanism}

In reality, environmental issues are complicated and involve multi-aspects. Only relying on the government's regulation, it is unable to look after everything at once. While the public's participation in environmental protection has been recognized as one of the important principles, and a-third party supervision is the best way. In Western developed countries, ENGO (environmental non-government organization), a not-profit organization without executive powers, is concerning with protecting environment and carrying out environmental public-service. The ENGO has the function of guidance and education in the folk, and owns the most influential and highly-regarded. In China, as public awareness of environmental protection, the number of ENGO is gradually rising, while, their ability is limited, and influence is less. To make up for the lack of government supervision, government would support and enhance the ENGO's status through attaching great importance to the related activities, and giving a full play to a third-party in supervision to ensure funds could be utilized reasonably and efficiently.

\subsection{Perfect the Environmental Protection Mechanism of Horizontal Financial Transfer Payment}

For a long time, China's financial transfer payment system is a vertical-oriented mode. In the mode, the central government works out the unified arrangement, and reallocates some wealthy area's part income to the poverty-stricken areas. However, the mode doesn't properly reflect the intrinsic unification between regional economic development and ecological service. As public services, the ecological environment has significant cross-regional characteristics. Belonging to different administrative region, the environmental benefited areas have different finance classes and scales. However, the economic development, industrialization and urbanization of the region inevitably is limited, whose main function is protecting the ecological environment, and the local government's choice is affected in the allocation of society's resources. The lost of the opportunity cost won't be fully compensated for the use of a single mode with vertical transfer payment. Especially located in the source of ecological protection, the western national region has got more financial transfer payments to support regional development in recent years. But data shows that the amount of capital is still not enough to change the financial strength in national regions, even cannot satisfy their demand for ecological protection and construction. All these would curb people's enthusiasm of environment resource protection, and lead to the adverse effect. Thus, the government should establish a vertical-oriented and criss-cross transfer payment mode to solve the problem of external effects of ecological environment. 


\subsubsection{Clear the Local Powers in Ecological Protection and Adjust the Achievements Assessment System}

In the Western Development Conference, the western region has positioned itself to enhance the capacity for sustainable development on the ecological construction and environmental protection, which just coincides with its main function. Local governments at all levels should further clarify the power division of environmental protection and ecological construction, and implement the environmental target responsibility system. At the same time, in order to encourage local government officials pay attention to environmental protection and other non-economic public goods, the system of all level governments' achievement in these areas should be adjusted from pursuing the GDP index of economic benefits to green GDP with environmental protection and GDP index, and by which improving local government and officers' attention.

4.3.2 Construct the Horizontal Financial Transfer Payment System of Ecological Compensation, and Strengthen Financial Support of the Northwest Ethnic Area in the Environmental Protection

In reality, the positive externality of environmental protection and the negative externality of damage is extremely obvious. It's unimaginable to protect environment totally depending on the spontaneous adjustment of the market itself, while not through the government intervene and correct. Therefore, the horizontal transfer payment system of ecological compensation is transferring part of financial funds from ecological benefit area to supply area, under the guidance of government, and setting up the equivalent exchange system in the close ecological area to fully reflect the symmetry rule between the cost and benefit of ecosystem service supply, meanwhile, straightening the local government supervision interest on the base of the division between economy and ecology.

To satisfy the need, firstly, the two-way responsibility system should be established that beneficiaries provide economic compensation for environmentalists, and dischargers provide compensation for environmental victims. The benefit compensation standard may refer to two criteria, one is correlation of benefit, usually directly adjacent area tends to high benefit from relevance, and should take the higher compensation standard. The second is the level of economic strength, usually the regional strength is stronger and more developed, should undertake more compensation.

Secondly, the ecological fund should be established by government entities at all levels participating, and take the market-oriented operation to collect and use. On the basis of fully considering the population scale, financial ability, and ecological benefits, the fund flow and limits should be determined.

\section{Conclusion}

From the viewpoint of scientific development, "Twelfth Five-Year Plan" is the period that China realizes the conversion of economic growth mode. Facing the enormous pressure rising from the transition of economic structure and the constraint on environmental resources, the financial policy should also cooperate with implementation, in order to achieve a resource-conserving and environment-friendly society. Under the current Chinese-style decentralization, the environmental protection cannot be spontaneous provisioned by local government, and it must rely on the central government's power to implement. Meanwhile, the restricted development zone and the prohibited development zone, which main function is ecological protection, are located in the inland, and their socio-economic development relatively backward. While the ecological restoration and maintenance often requires more capital expenditure, and the demand is not the local government can do on its own, which requires determining the green financial transfer payment mechanism associated with main functional areas to support the implementation.

And when the Northwest Ethnic Regions implement the restricted development and prohibited development strategy for the development priority zones, the government macroeconomic policy guidance focus on environmental protection and ecological construction and development of local characteristic industries. The important goal is to implement the fair tax policy which can prevent the depletion of resources and preserve ecosystems, and to increase the support to transfer payment and tax, giving full consideration to enhance the level of regional basic public service. Finally, the restricted and prohibited development zone achieves the abundance and prosperity with under-development. The establishment of green transfer payment system plays the crucial role to achieve the target.

\section{References}

Fu, Yong. (2010), Fiscal Decentralization, Government and Non-Economic Public Goods Provision. Economic Research Journal, (8), 4-15.

Lei, Z.Y., \& Cheng, A.H. (2009). An Analysis on the Balanced Effect of the Fiscal Transferring Payments Structure in Ethnic Areas. Ethno-National Studies. (4), 24-33.

Liang, J.J., \& Huang, Y. (2003). On Problems of Financial Transferable Payment of Economical Development in 
Ethnic Regions. Journal of the Central University for Nationalities (Philosophy and Social Sciences Edition), (5), 23-26.

Ma, J.X. (2007). Thinking of Perfecting the Financial Transfer Payment System of the Ethnic Autonomous Regions. Journal of InnerMongolia University (Humanities and Social Sciences, (6), 41-45.

Mao, J., Wang D.H., \& Bai, C, E. (2011). Intergovernmental Transfers for Ethnic Regions, Public Spending Difference and Economic Development Gap. Economic Research Journal, (S2), 75-86.

Wang, Y.L. (2008). The Optimization of the System of the Financial Transfer Payment for the Ethnic Areas: An analysis basing on History and Reality. Ethno-National Studies, (1), 29-38.

Wu, X.D., \& Wang, J.C. (2011). Analysis on Effect of Financial Transfer Payment to the Equal Public Services in Ethnic Areas. Economy and Management, (6), 77-81.

Zeng, Jifa. (2011), The Strategic thinking of building the green financial system in China. Sub National Fiscal Research, (2), 64-67.

Zhang, D.M. (2012). Problems concerning Financial Transfer Payment of Economical Compensation in China's Minority Areas and Possible Solution. Journal of Yunnan Nationalities University (Society Sciences), (9), 106-111.

Zhang, Lei, \& Huang, Xisheng. (2011). Constraints and Digestion Ideas of the Environmental Supervision Capacity-building in the "resources-saving and environment-friendly society" in China. Hebei Law Science, (7), 188-193. 